\title{
Saúde da Família: o desafio de uma atenção coletiva
}

\author{
Family $\mathrm{H}$ ealth: the challenge of a collective attention
}

Suzely Adas Saliba M oimaz ${ }^{1}$

Cristina Berger Fadel ${ }^{2}$

Sérgio Donha Yarid ${ }^{1}$

Diego Garcia Diniz ${ }^{1}$

${ }^{1}$ Departamento de Odontologia Infantil e Social, Faculdadede Odontologia deAraçatuba, Universidade Estadual Júlio deM esquita Filho. RuaJ osé Bonifácio 1.193, Vila M endonça. 16015-050 Araçatuba SP. sasaliba@foa.unesp.br ${ }^{2}$ Departamento de Odontologia, Universidade Estadual de Ponta Grossa.
Abstract The Family Health Strategies, incorporated by the M inistry of $\mathrm{H}$ ealth in 1994, has consolidated the national policy of health care that has as its main care focus the family. In this model, this institution constitutes the first object of attention, understood from its environment and interaction. In recent decades, the Brazilian family structure is suffering profound changes that directly affect the practices of health care. This study redeem the family concepts and ideas and their social representations and still prove and present the importance and the necessity of the use of theseampleinstruments of collectiveboarding in health area: the APGAR, the genogram and eco-map, using the environment observation and family history - crucial factors to the reality of the nuclear family diagnosis - for further planning of health action strategies. It was concluded that the current structure of the family require training from the health teams, for physical, cultural, biological and social points of the family context for the correct use of the instruments cited, important tools for collective approach in the public health area.

Key words Family relations, Professional-family relations, Family practice, Family health
Resumo A estratégia de Saúde da Família, incorporada pelo M inistério da Saúde, em 1994, veio consolidar a política nacional de atenção à saúde que tem como seu principal foco de atuação a família. N esse modelo, esta instituição passa a ser objeto primário de atenção, compreendida a partir do ambiente onde vive e de sua interação com o mesmo. N as últimas décadas, a estrutura familiar brasileira vem sofrendo profundas alterações, queinfluenciam diretamentenas práticas deatenção à saúde. Esse estudo buscou resgatar os conceitos e concepções de família, bem como de suas representações sociais, e ainda revelar e apresentar a importância e a necessidade do uso de instrumentos amplos de abordagem col etiva em saúdecomo o APGAR, o genograma e o ecomapa, que utilizam a observação do ambiente e do histórico familiar, fatores fundamentais para o diagnóstico da realidade do núcleo familiar, para posterior planejamento das estratégias de ações em saúde. Conclui-se que as atuais estruturas familiares exigem uma capacitação das equipes desaúde, em relação aos aspectos físicos, culturais, biológi cos e sociais do âmbito familiar, para a correta utilização dos instrumentos citados, importantes ferramentas para as abordagens coletivas no campo da saúde pública.

Palavras-chave Relações familiares, Profissional-família, M edicina de família e comunidade 
Introdução

O estudo de famílias tem se constituído em um vasto campo de pesquisa em diferentes áreas do conhecimento, por tratar de ricas e significantes interações que permeiam os diversos processos sociais em nosso país.

As discussões a respeito da família do século XXI têm acenado para reflexões mais amplas sobre as especificidades de cada núcleo familiar e não mais se restringem a estudos reducionistas, com model ose concepções preestabelecidos. Ainda, a exigência da valorização da família pelas políticas sociais brasileiras vem corroborando com a urgente expansão dos novos desenhos sobre os contextos familiares e de suas estratégias de intervenção, baseadas no plano de suas origens e repercussões ${ }^{1}$.

$\mathrm{N}$ a área da saúde e, em especial, na atual política nacional de atenção, essa importância assume um papel fundamental, visto que almeja estabelecer o núcleo familiar como seu principal foco de cuidado e atuação. A família brasileira vem sofrendo profundas variações na sua estrutura e organização, influenciadas por transformações nos panoramas sociais, políticos, culturais, econômicos e biológicos. Tal situação fica evidente pelas mudanças ocorridas nas estruturas familiares clássicas.

0 fato deo Estado vir pedindo apoio à família, na medida em que a identifica como lugar privilegiado para a promoção de políticas públicas, exemplificadas pela Estratégia de Saúde da Família, implica um profundo conhecimento sobre seu modo de vida, visando compreendê-la em toda a sua complexidade e diversidade para trabalhar com pessoas de uma forma integrada e vivenciar melhorias em seu existir ${ }^{2,3}$.

D esta forma, e considerando que, para o sucesso eo incremento das ações desenvolvidas pelas equipes de saúde da família no Brasil, a qual tem a família e não o indivíduo como uma unidade de ação programática, é essencial uma capacitação ampla e situacional a respeito do termo família, além do conhecimento de formas de avaliação de abordagem coletiva.

\section{O ser família: conceitos econcepções}

A palavra família provém do latim famulus, cujo significado remete aos termos criado, servidor, escravo doméstico. Essa terminologia, criada na Roma Antiga, foi aplicada originalmenteao conjunto de empregados de um senhor. Nesta épo- ca, havia o predomínio de uma estrutura familiar patriarcal, em que um vasto leque de pessoas se encontrava sob a autoridade do mesmo chefe. $M$ ais tarde, nos tempos medievais, as pessoas começaram a unir-se por meio de vínculos matrimoniais, formando assim novas famílias. Dessa família recém-organizada fazia também parte as descendências geradas, constituindo agora duas novas famílias, a paterna e a materna. Com a revolução francesa, surgiram os casamentos laicosno ocidentee, posteriormente, com a revolução industrial, tornaram-se frequentes os movimentosmigratóriospara cidadesmaiores, construídas ao redor dos complexos industriais. Estas mudanças demográficas originaram o estreitamento dos laços familiares e o surgimento de pequenas famílias, num cenário semelhante ao que existe hoje em dia ${ }^{4,5}$. Na cultura ocidental, uma família é definida especificamentecomo um grupo de pessoas de mesmo sangue, ou unidas legalmente, como no casamento e na adoção. Muitos etnólogos argumentam que a noção de "sangue" como elemento de unificação familiar deve ser entendida metaforicamente; dizem que, em muitas sociedades e culturas não ocidentais, a família é definida por outros conceitos quenão oslaços consanguíneos. Assim, a família poderia seconstituir em uma instituição normalizada por uma série de regulamentos de afiliação e alianças, aceitas pelos membros ${ }^{6}$.

Segundo Héritier ${ }^{7}$, não há possibilidade de estabelecer uma definição universal para o termo família. Já para Kaloustian ${ }^{8}$, família é o espaço indispensável para a garantia da sobrevivência do desenvolvimento eda proteção integral dosfilhos edemaismembros, independentemente do arranjo social ou da forma como se estrutura. Na perspectiva sociológica, Cohen $^{9}$ define família como uma das cinco maiores instituições humanas, uma vez que especificam os papeis sociais e os preceitos para o comportamento dos indivíduos.

Já nas pesquisas demográficas, segundo Goldani ${ }^{10}$, o conceito defamília tem variado em função da unidade de enumeração, que na maioria dos censos é o domicílio. Este, definido como grupo de pessoas que vivem em uma mesma moradia, costuma ser identificado, para efeito de análise, como família. Portanto, nesta definição de família, reside a associação de família à condição de residência comum, considerando-se como membros da unidade familiar as pessoas que vivem no mesmo domicílio. Segundo a autora, isto se justifica pelo fato que a estrutura domiciliar e o parentesco estão intimamente ligados e que o significado sociodemográfico seria 
0 mesmo. Acrescenta-se também uma reflexão sobre o conceito defamília nos censos, alertando que os propósitos de análise é que vão definir a unidade de referência. Para ela, a associação do conceito de família ao nível de convívio ou ligação doméstica tem a ver com a família como de finição de unidade de consumo, que seria o objetivo central da questão família para o censo de população. No entanto, em se pensando o papel da família em termos de sua dinâmica demográfica em geral, torna-se indispensável o controle de parentesco, sobretudo a identificação das unidades conjugais presentes no domicílio

M edeiros e Osório ${ }^{11}$ também destacam a importância da identificação dos núcleos familiares, com seus arranjos familiares e domiciliares, nas pesquisas de população. N elas, o grupo de pessoas que residem numa habitação é chamado de "domicílio" e os núcleos familiares são chamados de "famílias". Essa identificação permite a coleta de uma série de informações importantes nas quais "famílias" se referem aos arranjos domiciliares.

\section{Família esuas representações sociais}

A família, enquanto espaço de viver conjunto, tem se sobressaído nas novas abordagens em saúde coletiva, visto que é a principal detentora de grande parte das construções e representações sociais.

É a família que propicia os vínculos e aportes afetivos e, sobretudo, os subsídios necessários ao desenvolvimento eao bem- estar de seus componentes. Ela desempenha ainda um papel decisivo na educação formal e informal e, em seu ambiente, são absorvidos os valores culturais, éticos, morais e humanitários que aprofundam os comportamentos sociais e os laços de solidariedadehumana. Também, em seu interior, constroem-se, aprofundam-se e disseminam-se "marcas", positivas ou não, transmitidas entre as gerações ${ }^{12,13}$. As crenças e práticas de cada família devem ser profundamente estudadas e re conhecidas, visando-se minimizar conflitos entre a equipe de saúde, principal detentora do saber técnico-científico e a família, detentora do saber popular. Quando as diferenças na compreensão de um problema se estreitam, certamente aumenta-se a possibilidade de sucesso em seu enfrentamento ${ }^{14}$.

Elaéainda responsável pelo controledafunção reprodutora, pela socialização das crianças e por estratégias de segurança econômica de seus membros 5 . Do ponto de vista biológico, a família éum verdadeiro sistema de saúde para seus componentes, pois contém um modelo explicativo de saúde e de doença que compreende um conjunto de valores, crenças, conhecimentos e práticas, os quais guiam as ações da família no tratamento, prevenção e promoção da saúde. Esse sistema possui um processo de cuidar, em que a família passa a ser a principal supervisora do seu estado de saúde, adotando decisões e posturas próprias, no que se refere aos caminhos que deve seguir. Frente aos problemas, acompanha e avalia constantemente a saúde e a doença de seus componentes, pedindo ajuda a seus significantes e profissionais, na medida em que julguenecessária ${ }^{15,16}$.

A população e a família brasileira têm passado por muitas transformações, acompanhando os acontecimentos históricos, econômicos, sociais e demográficos acontecidos ao longo do tempo. Nas últimas décadas, as mudanças observadas na soci edade, como a diminuição da fecundidade e mortalidade, o aumento da longevidade dosidosos, proporcionado por melhorescondições de vida e saúde, os padrões de relacionamento entre os membros da família e o papel da mulher dentro e fora do espaço doméstico geraram mudanças significativas na constituição familiar, que refletem profundamente no cuidado à saúde.

Atualmente, as famílias são formadas por diversas estruturas. Isso é demonstrado através de dados oficiais divulgado pelo Instituto Brasileiro de Geografia eEstatística (IBGE). 0 núcleo tradicional, constituído por um casal efilhos, não é mais a única forma estrutural da família na sociedade brasileira, apesar deainda ser a principal. Embora a maior parcela das famílias ainda seja composta por casais com filhos $(53,3 \%)$, houve uma forte retração no número de famílias com essa estrutura (em 1981, o percentual de famílias desse tipo era de $65 \%)^{17}$.

A proporção de casais com filhos e com parentes também registrou queda. Em compensação, cresceu expressivamenteo número defamílias compostas por chefes mulheres e filhos sem a presença do cônjuge, fato esse gerado principalmente pela emancipação da mulher e a seu ingresso no mercado de trabalho. As famílias monoparentais femininas já são a segunda constituição familiar mais comum (17,8\%). O utras transformações menos significativas também são notadas, como 0 aumento da parcela de pessoas que moram sozinhas, que passou de $5,9 \%$ em 1981, para 9,2\% em 2001, e o ligeiro crescimento do percentual de casais sem filhos. Também, embora de forma menos expressiva, há um percen- 
tual mais alto defamílias com chefe homem com filhos sem cônjuge (Tabela 1) ${ }^{17}$.

Essa situação repercutiu também no aspecto jurídico, visto que, na discussão realizada por Dias $^{18}$ sobre o Código Civil Brasileiro, algumas das alterações ocorridas dizem respeito a essa instituição. Pelo código, nessa discussão, são consideradas famílias os grupos formados não só pelo casamento civil ou religioso, mas também pela união estável entre um homem e uma muIher ou por um conjunto de pessoas conduzido somente por um desses el ementos. Vale ressaltar que, anteriormente, uma união não validada pelo casamento formal era considerada "família ilegítima" e, seus frutos, "filhos ilegítimos", expressões que não cabem mais em nossa sociedade.

Deste modo, o conhecer e o reconhecer profundos dessas interações e configurações familiares constituem objetos de extrema importância para as práticas em saúde, visto que interferem, determinam e condicionam o processo decurae adoecer humano.

\section{A abordagem coletiva em saúde}

A família desempenha um papel importante na provisão de cuidado informal para seus membros. Há um geral reconhecimento, hoje em dia, de queela está no centro das funções decuidado. Uma grande parte do cuidado acontece no lar. A vida cotidiana doméstica écaracterizada pelo atendimento às necessidades físicas epsicológicas dos diferentes membros da família. É no seu contexto social que se sal vaguarda a saúde e se lida com as doenças. A família representa, na verdade, a unidade básica de atenção à saúde; é o primeiro nível de atenção à saúde ${ }^{19}$.

$\mathrm{Na}$ tentativa de reorganizar a atenção básica em saúde e em substituição ao então modelo assistencial, o M inistério da Saúde, em 1994, assumiu o desafio de incorporar, em seu plano de ações e metas prioritárias, as estratégias de Saúde da Família, embasadas nos princípios da universalidade, equidadeeintegralidadeda atenção ${ }^{20}$. Sob essa ótica, a estratégia utilizada no Programa Saúde da Família (PSF) busca a inversão do modelo assistencial vigente, centrado na cura de doenças, elegendo como ponto fundamental 0 estabelecimento de vínculos e a criação de laços de compromisso e de corresponsabilidade entre os profissionais de saúde e a população. Para tanto, faz-se necessária a mudança do objeto de atenção, desta vez voltada a grupos humanos, forma de atuação eorganização dos serviços, sob novas bases e critérios ${ }^{21}$.

Norteando as práticas propostas, o PSF prevê o diagnóstico de saúde da comunidade, o planejamento e programação com base na realidade local, a complementaridade, a abordagem multiprofissional, o sistema de referência e contrarreferência, a educação continuada, a integração intersetorial, o acompanhamento, a avaliação e o controle social. N esse modelo, a família passa então a ser objeto primeiro de atenção, compreendida a partir do ambiente onde vive e de sua interação com esse. Somado a essa dimensão, é importante entender que as relações entre as famílias e os serviços de saúde estão inseridas em um conjunto de determinantes soci-

Tabela 1. Evolução das famílias brasileiras.

\begin{tabular}{lrrrrr}
\hline & \multicolumn{1}{c}{1981} & \multicolumn{1}{c}{1990} & 2001 & Var (90-89) & Var (01-90) \\
\hline Total & 27.690 .498 & 38.002 .450 & 50.410 .713 & $37 \%$ & $33 \%$ \\
U nipessoal & 1.640 .088 & 2.648 .810 & 4.620 .602 & $62 \%$ & $74 \%$ \\
Duas ou mais pessoas sem parentesco & 56.936 & 60.591 & 50.965 & $6 \%$ & $-16 \%$ \\
Casal sem filho & 3.323 .938 & 4.822 .173 & 6.962 .106 & $45 \%$ & $44 \%$ \\
Casal sem filho e com parente & 469.781 & 599.213 & 865.652 & $28 \%$ & $44 \%$ \\
Casal com filho & 17.996 .023 & 23.153 .646 & 26.877 .887 & $29 \%$ & $16 \%$ \\
Casal com filho e com parentes & 2.095 .897 & 2.411 .749 & 2.538 .366 & $15 \%$ & $5 \%$ \\
Mulher chefe sem cônjuge com filho & 3.228 .417 & 5.293 .622 & 8.977 .637 & $64 \%$ & $70 \%$ \\
Mulher chefe sem cônjuge com filho & 577.824 & 892.115 & 1.506 .001 & $54 \%$ & $69 \%$ \\
e com parente & & & & & $43 \%$ \\
Homem chefe sem cônjuge com filho & 509.474 & 728.250 & 1.040 .111 & $43 \%$ \\
Homem chefe sem cônjuge com filho & 94.515 & 131.228 & 151.769 & $39 \%$ & $16 \%$ \\
e com parente & & & & &
\end{tabular}

Fonte: PNAD/IBGE 2005. 
ais, políticos e econômicos. Desta vez, não basta mais a intervenção e a recuperação isoladas do corpo biológico, visto que essas práticas não têm respondido de forma plena às necessidades de saúde da população. As ações devem ir além e demandam uma atenção que reconheça e considere a integralidade do ser humano e o impacto em sua qualidade de vida ${ }^{22}$

$\mathrm{Na}$ atenção à saúde, a observação e o histórico familiar são importantes estratégias para se obter informações para o planejamento das ações em saúde. Assim, considerando a necessidade de critérios de coerência entre as bases teóricas utilizadas, a disponibilidade das informações e a coleta de dados válidos e confiáveis, destacam-se 0 APGAR da família, o genograma e o ecomapa como valiosos instrumentos para a compreensão dos processos familiares e das relações com a comunidade, no exercício do planejamento e das intervenções em saúde pública.

O APGAR da família, proveniente da língua inglesa, Adaptação (Adaptation), Participação (Partnership), Crescimento (Growth), Afeição (Affection) e Resolução (Resolve), é um instrumento de avaliação destinado à reflexão da satisfação decada membro familiar. Nele são avaliados: a adaptação (como os recursos são compartilhados ou qual o grau de satisfação dos componentes com a atenção recebida, quando recursos familiares são necessários); a participação (como as decisões são compartilhadas ou qual a satisfação do membro da família com a reciprocidade da comunicação familiar e na resolução de problemas); o crescimento (como a promoção do crescimento écompartilhada ou qual a satisfação do membro da família com a liberdade disponível no ambiente familiar, para a mudança de papeis e para a concretização do crescimento emocional ou amadurecimento); afeição (como as experiências emocionais são compartilhadas ou qual a satisfação do membro da família com a intimidade e interação emocional no contexto familiar) e resolução (como 0 tempo é compartilhado ou qual a satisfação do membro familiar com o compromisso que tem sido estabelecido pelos seus própriosmembros) $)^{21,23}$.

O genograma é um instrumento elaborado por terapeutas familiares e tem sido amplamente adotado por profissionais de diversas áreas humanas e da saúde, como medicina, psicologia, serviço social, enfermagem, etc. Ele consiste na representação gráfica de informações sobre a família, evidenciando a dinâmica familiar e as relações entre seus membros. É um instrumento padronizado, no qual símbolos e códigos podem ser interpretados como uma linguagem comum aos interessados em visualizar e acompanhar a história familiar e os relacionamentos internos ${ }^{24}$ ${ }^{26}$. Esta ferramenta possibilita coletar informações qualitativas sobre dimensões da dinâmica familiar, como processos de comunicação, relações estabelecidas e equilíbrio/desequilíbrio familiar; representar visualmente a estrutura e dinâmica familiar, bem como de eventos importantes em sua história (como separação, nascimento e morte); auxiliar a família na identificação de cada um de seus membros como parte integrante de um grupo deindivíduos, quese relacionam entre si e com o ambiente, unidos por um comprometimento mútuo e configurando 0 conjunto de pessoas que consideram como sendo sua própria família; e verificar a interdependência entreos componentes, sugerindo queeventos ocorridos em um membro afetam direta ou indiretamente outros elementos. Ao resgatar essas informações, o genograma pode ser utilizado para disparar reflexões acerca de um problema presente no contexto amplo das relações que se apresentam, além de facilitar discussões sobre possíveis intervenções ${ }^{27,28}$.

Dentreas diversas vantagens da utilização do genograma, destaca-se a possibilidade de observar e analisar barreiras e padrões de comunicação entre as pessoas; explorar aspectos emocionais e comportamentais em um contexto de várias gerações; auxiliar os membros da família a identificar aspectos comuns e únicos de cada um deles; discutir e evidenciar opções de mudanças na família e prevenir o isolamento de um membro da família, independentemente da estrutura familiar. Ele pode ser considerado mais do que um instrumento para coleta de dados, sendo parte do processo terapêutico ${ }^{29}$.

A construção do genograma podeser iniciada logo no primeiro contato com os membros da família. Num processo de "conversa", muito mais do que de "entrevista", as informaç̧ões vão sendo coletadas de acordo com o significado atribuído por cada membro. Esse processo de envolvimento familiar na construção do seu próprio genograma pode resultar em importantes desdobramentos, tais como a promoção da saúde familiar, a conscientização de seus membros a respeito de sua influência sobre medidas capazes de favorecer a saúde e o bem-estar de sua unidadee, ainda, o empoderamento da família, permitindo aosindivíduos o acesso e o poder decisório sobre os determinantes do processo saúde-doença ${ }^{30}$.

Para situar uma família em suas relações na comunidade, destacamos o ecomapa. Esse instrumento é um diagrama das relações entre a família 
e a comunidade, utilizado para destacar e avaliar os apoios e suportes familiares disponíveis. É, essencialmente, um diagrama dos contatos da família com pessoas, grupos ou instituições, como escolas, serviços de saúde e comunidades religiosas. Pode representar a presença ou ausência de recursos sociais, culturais eeconômicos, sendo, eminentemente, o retrato de um determinado momento na vida dos membros da família. Uma família com poucas conexões com a comunidade e entre seus membrosnecessita demaior investimento dosprofissionais de saúde, em busca da melhoria de seu bem-estar e qualidade de vida $a^{31,32}$.

Vale lembrar que esses instrumentos de avaliação eintervenção podem ser utilizados deforma conjunta, de acordo com suas características e necessidade de cada família. Esses processos visam possibilitar aos familiares o repensar de suas próprias relações, a aquisição de confiança entre pesquisadores e familiares e a busca de suporte, dentro e fora do núcleo familiar.

Há tempos a literatura internacional aponta os benefícios da utilização do genograma e do ecomapa; entretanto, estesinstrumentos ainda são pouco divulgados no Brasil. Dentre suas principais características, destacam-se, tanto durante a investigação quanto no processo de atuação estratégica, o ser "facilitador" das relações entreprofissionais e entrevistados, visto que tornam a comunicação maisinformal epermitem autilização de vários recursos da linguagem não verbal ${ }^{33}$.

Contudo, há que se ter cautela em seu uso e aplicabilidade, uma vez que dispõem sobre relações dinâmicas eflexíveis que se transformam ao longo do tempo. Como instrumentos, mostramse manipuláveis, tanto pelos participantes quanto pelo entrevistador, devendo, portanto, o profissional da saúde estar muitíssimo bem capacitado para empregá-los ${ }^{32}$.

\section{Considerações finais}

Conclui-se que as atuais estruturas familiares brasileiras exigem uma capacitação das equipes de saúde em relação aos aspectos físicos, culturais, biológicos esociais do âmbito familiar para a correta utilização dos instrumentos de observação e análise do histórico da família, como o APGAR, o genograma e o ecomapa, importantes ferramentas para as abordagens coletivas no campo da saúde pública.

\section{Colaboradores}

SAS M oimaz trabalhou na concepção, revisão crítica e redação final da versão a ser publicada. CB Fadel eSD Yarid trabal haram na concepção e redação final. DG Diniz trabalhou na pesquisa bibliográfica, concepção eredação final. 
Referências

1. Blundo RG, M cdaniel C. The twenty-first century family. In: Bomar PJ, editor. Promoting health in families: applying family research and theory to nursing practice. Philadel phia: Saunders; 2004. p. 38-59.

2. Resta DG, Budó ML. D. A cultura e as formas de cuidar em família na visão de pacientes e cuidadores domiciliares. Acta Sci. Health Sci 2004; 26(1):53-60.

3. Itaboraí NR. A proteção social da família brasileira contemporânea: reflexões sobre a dimensão simbólica das políticas públicas. [site da Internet] 2005 [acessado em 2008 jul 03]:18. Disponível em: http:// www.abep.nepo.unicamp.br/docs/anais/outros/ FamPolPublicas/N athaliel taborai.pdf

4. Garbar C, Theodore FA. Família M osaico: as novas contribuições familiares. São Paulo: Augustus; 2000.

5. Stanhope M. Teorias e Desenvolvimento Familiar. In: Stanhope M, Lancaster J, organizadores. Enfermagem Comunitária: Promoção de Saúde de Grupos, Famílias e Indivíduos. Lisboa: Lusociência; 1999. p. 492-514.

6. Lyra LBC. Empresa familiar: entre 0 afetivo e o profissional [monografia]. Recife (PE): Universidade Católica de Pernambuco; 2007.

7. Héritier F. A coxa de Júpiter: Reflexões sobre os novos modelos de procriação. Rev Est Fem 2000; 8(1):98-114.

8. Kaloustian SM. Família brasileira, a base de tudo. 2a ed. São Paulo: Cortez; Brasília: UNICEF; 1997. p. 11-15.

9. Cohen BJ. Família. In: Cohen BJ, organizador. Sociologia geral. São Paulo : M cGraw-Hill do Brasil; 1980. p. 67-75.

10. Goldani AM. A demografia "formal" da família: técnicas e dados censitários. In: Anais do IV Encontro Nacional de Estudos Populacionais (ABEP); Caxambu; 1984. p. 1257-1296.

11. Medeiros M, Osório RG. Arranjos domiciliares e arranjos nucleares no Brasil: classificação e evolução de 1977 a 1998. [site da Internet]. 2001 [acessado 2008 jul 10]; [cerca de 45 p]. Disponível em: http://www.ipea.gov.br/pub/td/td_2001/td_788.pdf

12. Wagner $H L$, Wagner $A B P$, Talbot $Y$. Aplicação do pensamento sistêmico no trabalho em Saúde da Família. Rev Bras Med Fam 2004; 1:29-35.

13. Draibe $S M$. Por um reforço da proteção à família: contribuição à reforma dos programas de assistência social no Brasil. In: Kaloustian SM, organizador. Família brasileira: a base de tudo. 4a ed. São Paulo: Cortez, Brasília: UNICEF; 2000.

14. Silveira M L. Família: Conceitos sócio-antropológicos básicos para o trabalho em saúde. Família. Saúde e Desenvolvimento 2000; 2(2):58-64.

15. Elsen I. Cuidado familial: uma proposta inicial de sistematização conceitual. In: Elsen I, M arcon SS, Silva MRS. 0 viver em família e sua interface com a saúde e a doença. M aringá: UEM ; 2002. p. 11-24.

16. Serapioni M. O papel da família e das redes primárias na reestruturação das políticas sociais. Cien Saude Colet 2005; 10(Supl.):243-253.
17. Instituto Brasileiro de Geografia e Estatística. Dados históricos dos censos. [site da Internet] [acessado em 2008 jul. 06]. Disponível em: www.ibge.gov.br/home/ estatistica/populacao/censohistorico/default_hist. shtm

18. Dias M B. Novos Tempos, Novos Termos. Artigos Jurídicos [periódico na Internet] 2004 [acessado 2008 jan 25]. Disponível em: http://www.advogado.adv.br/ artigos/2004/mariaberenicedias/novostempos.htm

19. Ronzani TM, Silva CM . O Programa Saúde da Família segundo profissionais de saúde, gestores e usuários. Cien Saude Colet 2008; 13(1):23-34.

20. Brasil. M inistério da Saúde. Secretaria da Assistência à Saúde. Coordenação da Saúde da Comunidade. Saúde da Família: uma estratégia para a reorientação do modelo assistencial. Brasília: Ministério da Saúde; 1998.

21. Rocha SMM, Nascimento LC, Lima RAG. Enfermagem pediátrica e abordagem da família: subsídios para 0 ensino de graduação. Rev. Latino-Am. Enfermagem 2002; 10(5):709-714.

22. Athayde ES, Gil CRR. Possibilidades do uso do genograma no trabalho cotidiano dos médicos das Equipes de Saúde da Família de Londrina. Rev Esp Saude 2005; 6(2):13-22.

23. Shortridge-Baggett $L, M$ almgreen $C$, Wantroba $A$. $M$ étodo de avaliação estruturada como instrumento de assistência familiar: Avaliação do Apgar Familiar. Família, Saúde e Desenvolvimento [periódico na Internet]. 2007 [acessado 2008 jan 22]:6(2):[cerca de 9 p.]. Disponível em: http://ojs.c3sl.ufpr.br/ojs2/ index.php/refased/article/view/8059

24. Moysés S.T Talbot $Y$, Czeczko NG, Nassif PAN, Wagner ABP, Oliveira E, M oyses SJ, Wagner HL. Ferramenta de descrição da família e dos seus padrões de relacionamento - Genograma - uso em saúde da família. In: Abordagem familiar sistêmica. Curso Básico para o Programa Saúde da Família. Rio Grande: Fazenda; 1997.

25. 25. Landim FLP, Araújo AF, Ximenes LB, Varela ZM V. Comunidade mutirante: características familiares e suas redes de suporte social. Rev Bras Prom Saúde 2004; 17(4):177-186.

26. Alonso JAB. Individuo y familia. Rev de la SEM G 2004; 62:169-175.

27. Watts $C$, Shrader $E$. The genogram: a new research tool to document patterns of decision-making, conflict and vulnerability within households. $\mathrm{H}$ eal Pol Plan 1998; 13(4):459-464.

28. Olsen S, Budley-Brown S, Mc Mullen P. Case for blending pedigrees, genogram and ecomaps: nursing's contribution to the "big picture". Nurs Health Sci 2004; 6(4):295-308.

29. Tarko MA, Reed K. Family assessment and intervention. In: Bomar PJ, editor. Promoting health in families: applying family research and theory to nursing practice. $3^{\text {rd }}$ ed. Philadelphia: Saundres; 2004. p. 274-303.

30. Wright LM, Leahey M. Enfermeiras e famílias - uma guia para avaliação e intervenção na família. 3 a ed. São Paulo: Roca; 2002. 
31. Ross B, Cobb KL. Family Nursing: A nursing Process Approach. Redwood City, California: AddisonWesley Nursing; 1990.

32. Nascimento LC, Rocha SM M, H ayes VE. Contribuições do genograma e do ecomapa para estudo de famílias em enfermagem pediátrica. Texto Contexto Enferm 2005; 14(2):180-286.

33. Yurss I. Atención a la familia: otra forma de enfocar los problemas de salud en atención primaria instrumentos de abordaje familiar. An. Sist Sanit Nav 2001; 24(2):73-82.

Artigo apresentado em 13/03/2008

Aprovado em 03/07/2008

Versão final apresentada em 06/08/2008 